\title{
DANOS CAUSADOS PELA LARVA-ALFINETE EM MILHO EM CONDIÇÕES DE CAMPO
}

\author{
ANA PAULA SCHNEID AFONSO DA ROSA ${ }^{1}$, LAUREN BITTENCOURT MEDINA ${ }^{2}$, \\ LETICIA HELLWIG ${ }^{2}$, CALISC DE OLIVEIRA TRECHA ${ }^{2}$ e MARCUS VINÍCIUS FIPKE ${ }^{3}$
}

\author{
'Embrapa Clima Temperado, Pelotas, RS, Brasil; ana.afonso@embrapa.br; \\ ${ }^{2}$ Universidade Federal de Pelotas, laurenmedina@live.com; leticia_hellwig@hotmail.com; calistrecha@gmail.com; \\ ${ }^{3}$ Universidade Federal do Rio Grande do Sul, marfipke@gmail.com
}

Revista Brasileira de Milho e Sorgo, v.16, n.1, p. 153-160, 2017

\begin{abstract}
RESUMO - O objetivo desse trabalho foi avaliar os danos causados por diferentes densidades larvais de Diabrotica speciosa em milho BG $7060 \mathrm{H}$ em condições de campo. O experimento foi realizado na safra 2012/2013, na Embrapa Clima Temperado (S 3149.268 e W 52²7.472). Cada parcela foi constituída de seis linhas de $5 \mathrm{~m}$ x $0,70 \mathrm{~m}$. As plantas foram infestadas com 0, 5, 15, 30 e 40 larvas/planta. Foram avaliados, 64 dias após a infestação, o peso e o comprimento e dano em raízes e, na ocasião da colheita, a altura da planta e inserção da espiga e o rendimento. Não foi observada redução significativa do peso de raízes infestadas com larvas de $D$. speciosa. O comprimento das raízes foi numericamente maior quando não houve infestação larval, e a altura de plantas e a inserção da espiga não foram influenciadas pela infestação. De acordo com a escala de Iowa State 1-6, independentemente do número de larvas inoculadas às raízes, os danos foram abaixo de 2,0 $(1,29$ - 1,74). Pela escala de Iowa 0-3, verificou-se dano inferior a $0,75(0,23-0,60)$. Em relação ao rendimento, de modo geral, à medida que aumentou a densidade larval, houve redução no rendimento.
\end{abstract}

Palavras-chave: Diabrotica speciosa, injúrias, infestação artificial, raízes.

\section{DAMAGE CAUSED BY CORN ROOTWORM IN CORN FIELD CONDITIONS}

\begin{abstract}
The aim of this study was to evaluate the damage caused by different larval densities of Diabrotica speciosa in maize BG $7060 \mathrm{H}$ under field conditions. The experiment was conducted in the field in 2012/2013, at Embrapa Clima Temperado ( $31^{\circ} \mathrm{S} 52^{\circ} \mathrm{W} 49,268$ and 27,472). Each plot consisted of six rows $5 \mathrm{~m} \times 0.70 \mathrm{~m}$ and the cultivar used was BG $7060 \mathrm{H}$. The plants were infested with 5, 15, 30 and 40 larvae/plant, and there was a control (no larvae). The damage, weight and length of roots were evaluated 64 days after infestation (DAI) (22/01/2013). At the harvest, plant and ear height and yield were evaluated. No significant reduction in the weight of roots infested with larvae of beetles was observed. The root length was numerically higher when there was no larval infestation. Plant and ear height was not affected by the infestation. According to Iowa State 1-6 damage scale, regardless of of the number of larvae inoculated to roots, damages were below 2.0 (1.29 to 1.74). According to scale of Iowa 0-3, there was damage less to $0.75(0.23$ to 0.60$)$. In relation to yield, it was observed that, in general, as increased larval density, there was a reduction in yield.
\end{abstract}

Keywords: Diabrotica speciosa, injuries, artificial infestation, roots. 
O gênero Diabrotica Chevrolat inclui um dos mais importantes insetos que causam danos em plantas. Há muitas décadas, a importância de Diabrotica tem aumentado em razão das injúrias causadas por ela, tanto em espécies nativas quanto em espécies cultivadas no continente americano (Walsh, 2003). Estima-se que em 2002 as perdas de rendimento decorrentes do ataque de larvas do gênero Diabrotica e custos com controle ultrapassaram U\$ 1 bilhão (Mitchell et al., 2002).

Diabrotica speciosa (Germar, 1824) (Coleoptera: Chrysomelidae) é uma praga polífaga que afeta diversas culturas no Brasil (Haji, 1981; Walsh, 2003). $\mathrm{Na}$ fase larval é importante praga do milho (Zea mays L.), consumindo o sistema radicular das plantas (Marques et al., 1999). Na fase adulta, causa sintoma semelhante ao da lagarta de Spodoptera frugiperda (Rosa et al., 2013), consome os estilo-estigmas antes da fecundação, provocando falha de grãos nas espigas (European and Mediterranean Plant Protection Organization, 2005).

No sistema radicular os sintomas são escoriações nas raízes primárias, formando galerias e destruição das raízes secundárias. Quando os danos ocorrem nas raízes adventícias, ocorre o tombamento das plantas denominado "pescoço de ganso" ou "milho ajoelhado". O consumo de raízes também reduz significativamente o rendimento de grãos, pois interfere na taxa fotossintética (Urias-Lopez et al., 2000), reduz a capacidade da planta absorver água e nutrientes (Hou et al., 1997), tornando-a menos produtiva e mais suscetível às doenças radiculares e tombamento, acarretando perdas de produção (Khaler et al., 1985).

A lesão decorrente do ataque larval ocorre, geralmente, do terceiro ao sexto nós de raízes adventícias, pois o desenvolvimento dessas raízes coincide com o tempo de eclosão dos ovos e das larvas em desenvolvimento (Riedell, 1990).

As larvas do gênero Diabrotica se distribuem em "reboleira", sendo alta a variabilidade: podem ocorrer de 0 a 100 larvas por planta (Mayo, 1986). Segundo Bergman et al. (1981), cerca de 90\% das larvas se concentram ao redor das plantas, sendo o primeiro ínstar disperso e os demais concentrados no raio de $10 \mathrm{~cm}$ em torno do sistema radicular. Em razão dessa característica, a melhor forma de avaliação de danos causados por larvas é a avaliação do sistema radicular (Mayo, 1986). Os danos mensurados através de uma escala de notas desenvolvida por Hills e Peters (1971) são considerados o padrão para a maioria dos trabalhos de avaliação de inseticidas para o controle da larva de Diabrotica spp.

De acordo com Branson et al. (1980), há uma correlação de 0,54 para danos nas raízes e rendimento de grãos. Os autores demonstraram que uma nota 2 de dano nas raízes, numa escala de seis pontos, resultou em aproximadamente 4\% na redução da produtividade. Segundo Mayo (1984), danos nas raízes de 2,5 a 3,0 nessa escala têm sido utilizados como sendo o nível de dano econômico (NDE). Sutter et al. (1989) comentam que apenas quando o dano alcança níveis entre 4,0 e 5,0 se justificaria o controle econômico com inseticidas, porém Davis (1994) considera níveis menores $(2,5$ a 3,0$)$ para culturas com maior valor agregado como silagem, milho doce e cultura irrigada, cujos níveis de produtividade esperados são mais elevados.

Este trabalho teve como objetivo avaliar os danos causados por diferentes densidades larvais de D. speciosa em milho em condições de campo. O experimento foi realizado na safra 2012/2013, conduzido em campo na Estação Experimental Terras Baixas da Embrapa Clima Temperado, em Capão do 
Leão-RS, nas coordenadas geográficas S 3149.268 e W 52 27.472. A cultivar de milho BG $7060 \mathrm{H}$ foi semeada, adubada e manejada de acordo com as recomendações técnicas para a cultura (Reunião Técnica Anual do Milho, 2013).

Cada parcela foi constituída de seis linhas de $5 \mathrm{~m}$ de comprimento com $0,70 \mathrm{~m}$ de espaçamento, sendo que quatro linhas centrais foram utilizadas para as observações.

Os ovos de D. speciosa dispostos em solução ágar:água foram inoculados em plântulas de milho 10 dias após a emergência (20/11/2012). Os ovos para infestação foram obtidos da criação estoque de D. speciosa proveniente do Núcleo de Manejo Integrado de Pragas da Embrapa (NUMIP), mantida em seedlings de milho, segundo metodologia de Milanez (1995).

Em cada parcela, utilizaram-se as quatro linhas centrais (parcela útil), e em cada linha, 10 plantas foram infestadas com diferentes densidades populacionais de ovos de D. speciosa, totalizando 40 plantas infestadas por parcela. As plantas foram infestadas com $5,15,30$ e 40 larvas por planta, além da testemunha (sem larvas), os quais constituíram os tratamentos.

Foram arrancadas 20 plantas para a primeira avaliação [64 dias após a infestação (DAI) (22/01/2013)], com raiz juntamente com o solo que

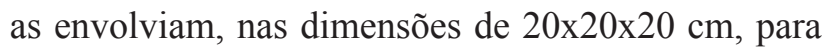
avaliação de peso da raiz, comprimento de raízes e danos. Após lavagem individual com água sob pressão, elas foram avaliadas utilizando-se escala de danos de Iowa State 1-6 (Hills \& Peters, 1971), e escala de Iowa 0-3 (Oleson et al., 2005) e as 20 plantas restantes foram avaliadas na colheita.

$\mathrm{O}$ delineamento experimental utilizado foi em blocos ao acaso contendo cinco tratamentos e quatro repetições, os resultados obtidos nas avaliações foram submetidos à análise de variância e as médias dos tratamentos, comparadas pelo teste de Tukey, a $5 \%$ de probabilidade, utilizando o programa Genes (Cruz, 2010).

Para a variável peso (g) de raiz (Tabela 1$)$, não foi observada redução significativa do peso em relação ao aumento da densidade larval. As densidades larvais não diferiram significativamente entre si, no entanto, a única diferença verificada foi para a densidade de 5 larvas/planta em relação à testemunha, em que o maior peso de raízes foi observado quando houve a infestação larval. De acordo com Ivezich et al. (2011), as plantas de milho são capazes de desenvolver resistência natural ao ataque de Diabrotica spp. através do desenvolvimento compensatório de raízes, fazendo com que o peso seja maior por causa da emissão de novas raízes provocadas pelo dano do inseto (Spike \& Tollefson, 1989).

Estudos conduzidos por Turpin (1972) indicam que larvas de D. v. virgifera recém-eclodidas precisam movimentar-se no interior da camada do solo à procura de alimento, e as partículas grosseiras de areia presentes no solo podem causar efeito abrasivo, danificando suas cutículas em ambiente seco, podendo levá-las à morte por desidratação. Este fator pode ter favorecido o maior peso de raízes quando as plantas foram infestadas com diferentes densidades larvais, pois a área de condução do experimento foi irrigada através de sistema linear de aspersão, proporcionando condições ideais de locomoção das larvas de $D$. speciosa. A constituição física de solo influencia na sobrevivência de larvas onde o aumento do conteúdo de argila aumenta a sobrevivência (Turpin \& Peters, 1971). Para as condições de realização do experimento, o solo do tipo planossolo hidromórfico fornece condições boas para a movimentação e sobrevivência das larvas. 
Tabela 1. Peso $(\mathrm{g})$ e comprimento $(\mathrm{cm})$ de raízes, altura de plantas $(\mathrm{cm})$ e inserção da espiga $(\mathrm{cm})$ de milho BG 7060 H submetido a diferentes infestações de larvas de Diabrotica speciosa. Capão do Leão-RS, 2013.

\begin{tabular}{ccccc}
\hline & \multicolumn{2}{c}{ Raízes } & $\begin{array}{c}\text { Altura de } \\
\text { plantas (cm) }\end{array}$ & $\begin{array}{c}\text { Inserção da } \\
\text { espiga (cm) }\end{array}$ \\
\cline { 2 - 5 } $\mathbf{0}$ & Peso (g) & Comprimento (cm) & $236,9 \mathrm{a}$ & $126,9 \mathrm{a}$ \\
$\mathbf{5}$ & $124,5 \pm 15,80 \mathrm{a}$ & $18,4 \pm 0,64 \mathrm{a}$ & $221,6 \mathrm{a}$ & $120,6 \mathrm{a}$ \\
$\mathbf{1 5}$ & $101,7 \pm 15,80 \mathrm{ab}$ & $17,4 \pm 0,78 \mathrm{a}$ & $230,9 \mathrm{a}$ & $122,8 \mathrm{a}$ \\
$\mathbf{3 0}$ & $101,0 \pm 13,62 \mathrm{ab}$ & $17,1 \pm 0,54 \mathrm{a}$ & $240,3 \mathrm{a}$ & $125,0 \mathrm{a}$ \\
$\mathbf{4 0}$ & $96,9 \pm 13,15 \mathrm{ab}$ & $17,7 \pm 0,72 \mathrm{a}$ & $235,9 \mathrm{a}$ & $130,0 \mathrm{a}$ \\
\hline $\mathbf{C V} \mathbf{( \% )}$ & 18,08 & 8,64 & 7,18 & 7,09 \\
\hline
\end{tabular}

O comprimento das raízes foi numericamente maior quando não houve infestação larval, no entanto, sem diferir significativamente das plantas com infestação larval (Tabela 1). Esses dados corroboram a teoria da compensação de raízes quando há dano de larvas no sistema radicular (Ivezich et al., 2011), pois não havendo dano (0 larvas/planta) não houve crescimento de raízes secundárias, havendo maior desenvolvimento (em comprimento) das raízes primárias.

A altura de plantas e a altura da inserção da espiga não foram influenciadas pela infestação no sistema radicular do milho (Tabela 1), evidenciando que a escolha de híbridos de alto vigor e adaptados às condições locais (recomendados) é fundamental para o Manejo Integrado de Pragas.

Um dos grandes desafios técnicos do Brasil está em como avaliar os danos causados por D. speciosa em milho. Neste trabalho essa dificuldade ficou claramente evidenciada. A escala proposta por Hills e Peters (1971) é considerada padrão para a maioria dos trabalhos de avaliação de inseticidas para o controle de larvas de Diabrotica spp. (Mayo, 1986). Observou-se que se utilizando essa escala, os danos, independentemente do número de larvas inoculadas às raízes, foi abaixo de 2,0 (1,29 - 1,74) (Figura 1), ou seja, com sinais de alimentação evidente, sem apresentar raízes destruídas numa extensão de $4 \mathrm{~cm}$. Pela escala de Oleson et al. (2005), considerada mais precisa por ter por base a proporção de raízes nodais que contêm sintomas de lesão por alimentação das larvas, indicando que a relação entre a escala numérica e a quantidade de lesão da raiz é linear, verificou-se dano inferior a $0,75(0,23$ - 0,60) (Figura 1). De acordo com as duas escalas utilizadas para avaliação, não foi verificado nível de dano econômico à cultura em função da alimentação de larvas de $D$. speciosa na raiz, no entanto, a presença de larvas nas raízes pode causar alterações na fisiologia da planta de milho que podem interferir no desenvolvimento da planta. 
Em relação ao rendimento, observou-se que, de modo geral, à medida que aumentou a densidade larval, houve redução no rendimento (Figura 2). No entanto, não foi observada significância do coeficiente de regressão, corroborando com a hipótese de que a presença de larvas no sistema radicular poderá afetar a fisiologia da planta. Estudos conduzidos por Marques et al. (1999) corroboram os resultados obtidos neste trabalho, pois os autores verificaram relação positiva entre aumento de densidade de lar- vas de $D$. speciosa no sistema radicular do milho e o dano na raiz. Estudos conduzidos anteriormente (Davis, 1994) utilizaram grande quantidade de larvas e ovos para infestação larval. Contudo, a partir dos resultados aqui obtidos, fica comprovado o potencial de dano de larvas de $D$. speciosa em milho, mas cabe ressaltar a grande dificuldade de avaliação de danos em raízes, sendo necessária a busca por metodologias mais eficazes, rápidas e que demandem menos mão de obra.

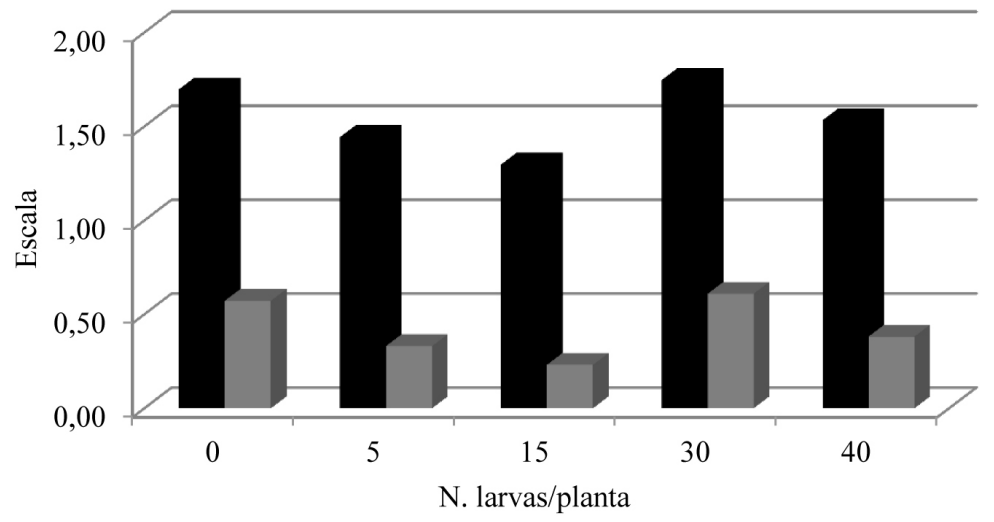

- Escala de Iowa State 1-6 Escala de Iowa 1-3

Figura 1. Avaliação de danos de Diabrotica speciosa em raízes de milho aos 64 dias após infestação através da escala Iowa State 1-6 (Hills \& Peters, 1971) e escala de Iowa 1-3 (Oleson et al., 2005). Capão do Leão-RS. 2013.

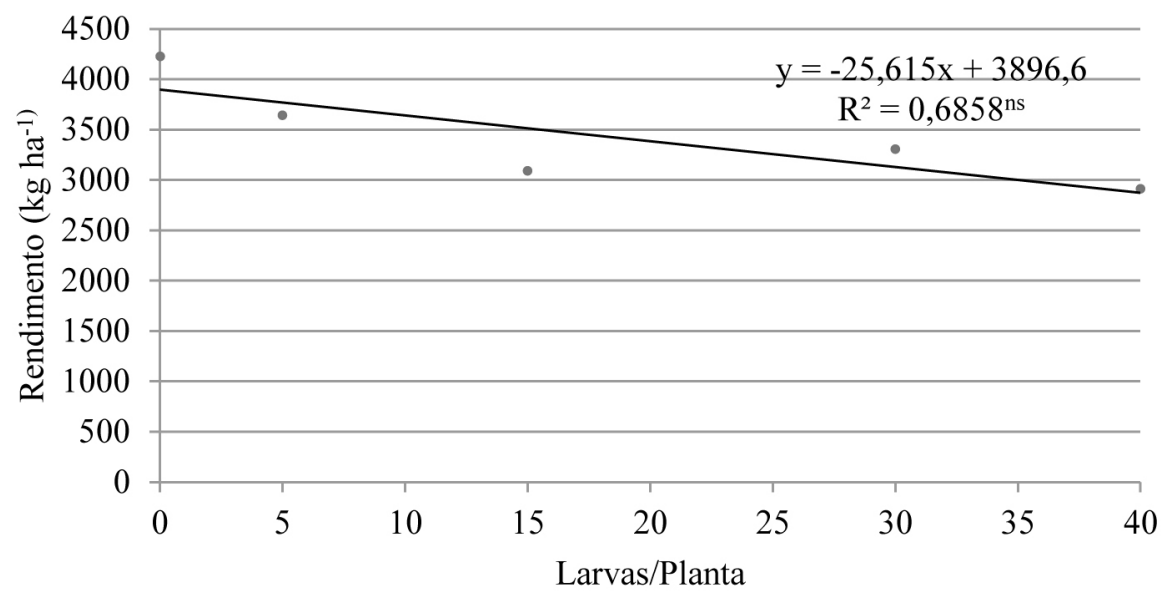

Figura 2. Rendimento de grãos $\left(\mathrm{Kg} \mathrm{ha}^{-1}\right)$ de plantas de milho submetidas à infestação de larvas de Diabrotica speciosa. Capão do Leão-RS, 2012/2013; ns: não significativo pelo teste F. 
Conclui-se que o aumento do número de larvas de Diabrotica speciosa em raízes de milho poderá interferir no rendimento.

\section{Agradecimentos}

Os autores expressam seus agradecimentos ao fundo Embrapa/Monsanto pelo aporte de recursos.

\section{Referências}

BERGMAN, M. K.; TOLLEFSON, J. J.; HINZ, P. N. Sampling scheme for estimating populations of corn rootworm larvae. Environmental Entomology, College Park, v. 10, p. 986-990, 1981.

DOI: $10.1093 / \mathrm{ee} / 10.6 .986$.

BRANSON, T. F.; SUTTER, G. R.; FISHER, J. R. Plant response to stress induced by artificial infestations of western corn rootworm. Environmental Entomology, College Park, v. 9, p. 253-257, 1980.

DOI: $10.1093 / \mathrm{ee} / 9.2 .253$.

CRUZ, C. D. Programa Genes: aplicativo computacional em genética e estatística experimental. Viçosa, MG: UFV, 2010. Disponível em: <http://www.ufv.br/dbg/genes/genes.htm>. Acesso em: 16 out. 2012.

DAVIS, P. M. Comparison of economic injury levels for western corn rootworm (Coleoptera: Chrysomelidae) infesting silage and grain corn. Journal of Economic Entomology, College Park, v. 87, n. 4, p. 10861090, 1994

DOI: $10.1093 /$ jee/87.4.1086.

\section{EUROPEAN AND MEDITERRANEAN PLANT} PROTECTION ORGANIZATION. Diabrotica speciosa (Germar) (Coleoptera: Chrysomelidae). Luxemburgo, 2005. p. 374-376. (Bulletin, 35). Luxemburgo. Disponível em: $<$ https://www.eppo.int/.../data sheets/.../DS_Diabrotica_speciosa.pdf $>$. Acesso em: 13 out. 2015.
FISHER, J. R. Comparison of controlled infestations of Diabrotica virgifera virgifera and Diabrotica barberi (Coleoptera: Chrysomelidae) on corn. Journal of Economic Entomology, College Park, v. 78, p. 14061408, 1985.

DOI: $10.1093 /$ jee/78.6.1406.

HAJI, N. F. P. Biologia, dano e controle do adulto de Diabrotica speciosa (Germar, 1824) (Coleoptera: Chrysomelidae) na cultura da batatinha (Solanum tuberosum L.). 1981. 53 f. Tese (Doutorado em Agronomia) - Escola Superior de Agricultura Luiz de Queiroz, Universidade de São Paulo, Piracicaba, 1981.

HILLS, T. M.; PETERS, D. C. A method of evaluating post planting pecticide treatments for control of western corn rootworm larvae. Journal of Economic Entomology, College Park, v. 64, p. 764-765, 1971.

HOU, X.; MEINKE, L. J.; ARKEBAUER, T. J. Soil moisture and larval western corn rootworm injury: influence on gas exchange parameters in corn. Agronomy Journal, Madison, v. 89, p. 709-717, 1997.

DOI: 10.2134/agronj1997.00021962008900050001x.

IVEZICH, M.; RASPUDICH, E.; MAJICH, I.; TOLLEFSON, J.; BRMEZ, M.; SARAJLICH, A.; BRKI$\mathrm{CH}$, A. Root compensation of seven maize hybrids due to western corn rootworm (Diabrotica virgifera virgifera LeConte) larval injury. Bulgarian Journal Agriculture Science, Croatia, v. 17, n. 1, p. 107-115, 2011.

KHALER, A. L.; OLNESS, A. E.; SUTTER, G. R.; DYBING, C. D.; DEVINE, O. J. Root damage by corn rootworm and nutrient content in maize. Agronomy Journal, Madison, v. 77, n. 5, p. 769-774, 1985.

DOI: 10.2134/agronj1985.00021962007700050023x.

MARQUES, G. B. C.; ÁVILA, C. J.; PARRA, J. R. P. Danos causados por larvas e adultos de Diabrotica speciosa (Coleoptera: Chrysomelidae) em milho. Pesquisa Agropecuária Brasileira, Brasília, DF, v. 34, n. 11, p. 1983-1986, 1999.

DOI:http://dx.doi.org/10.1590/S0100-204X1999001100002. 
MAYO, Z. B. Field evaluation of insecticides for control of larvae of corn rootworms. In: KRYSAN, J. L.; MILLER, T. A. (Ed.). Methods for the study of pest Diabrotica. New York: Springer, 1986. p. 183-203.

MAYO, Z. B. Influences of rainfall and sprinkler irrigation on the residual activity of insecticides applied to corn to control of adult western corn rootworm (Coleoptera: Chrysomelidae). Journal of Economic Entomology, College Park, v. 77, n. 1, p. 190-193, 1984.

DOI: $10.1093 /$ jee/77.1.190.

MILANEZ, J. M. Técnicas de criação e bioecologia de Diabrotica speciosa (Germar, 1824) (Coleoptera: Chrysomelidae). 1995. 102 f. Tese (Doutorado em Entomologia) - Escola Superior de Agricultura Luiz de Queiroz, Universidade de São Paulo, Piracicaba, 1995.

MITCHELL, P.; GRAY, M. E.; STEFFEY, K. L. Composed error model for insect damage functions: rotation resistant western corn rootworm in Illinois. College Station: Texas A\&M University, 2002. Manuscrito não publicado.

OLESON, J. D.; PARK, Y, L.; NOWATZKI, T. M.; TOLLEFSON, J. J. Node-injury scale to evaluate root injury by corn rootworms (Coleoptera: Chrysomelidae). Journal of Economic Entomology, Lanham, v. 90, n. 1, p. $1-8,2005$.

DOI: 10.1603/0022-0493-98.1.1.

REUNIÃO TÉCNICA ANUAL DO MILHO, 58., REUNIÃO TÉCNICA ANUAL DO SORGO, 41., 2013, Pelotas. Indicações técnicas para o cultivo de milho e de sorgo no Rio Grande do Sul safras 2013/2014 e 2014/2015. Brasília, DF: Embrapa, 2013. 124 p.

RIEDELL, W. E. Rootworm and mechanical damage effects on root morphology and water relations in maize. Crop Science, Madison, v. 30, p. 628-631, 1990.

DOI: $10.2135 /$ cropsci1990.0011183X003000030031x.
ROSA, A. P. S. A. da; TRECHA, C. O.; LIMA, C. V.; TEODORO, J. S.; MEDINA, L. B.; HELLING, L. Flutuação populacional e danos de Diabrotica speciosa (Germar, 1824) (Coleoptera: Chrysomelidae) na parte aérea do milho na safra 2011/2012 em Capão do Leão, RS. Pelotas: Embrapa Clima Temperado, 2013. 4 p. (Embrapa Clima Temperado. Comunicado Técnico, 308).

SPIKE, B. P.; TOLLEFSON, J. J. Relationship of root ratings, root size, and root regrowth to yield of corn injured by western corn rootworm (Coleoptera: Chrysomelidae). Journal of Economic Entomology, Columbia, v. 82, p. 1760-1763, 1989.

DOI: $10.1093 /$ jee/82.6.1760.

SUTTER, G. R.; BRANSON, T. F.; FISHER, J. R.; ELLIOT, N. C.; JACKSON, J. J. Effect of insecticide treatments on root damage ratings of maize in controlled infestations of western corn rootworms (Coleoptera: Chrysomelidae). Journal of Economic Entomology, College Park, v. 82, p. 1792-1798, 1989.

DOI: $10.1093 /$ jee/82.6.1792.

TURPIN, F. T. Western corn rootworm. West Lafayette: Purdue University, 1972. 5 p. (Publication E-201).

TURPIN, F. T.; PETERS, D. C. Survival of southern and western corn rootworm larvae in relation to soil texture. Journal of Economic Entomology, College Park, v. 64, p. 1448-1451, 1971.

DOI: $10.1093 /$ jee/64.6.1448.

URIAS-LOPEZ, M. A.; MEINKE, L. J.; HIGLEY, L. G.; HAILE, F. J. Influence of western corn rootworm (Coleoptera: Chrysomelidae) larval injury on photosynthetic rate and vegetative growth of different types of maize. Environmental Entomology, Hyattsville, v. 29, p. 861-867, 2000.

DOI: 10.1603/0046-225X-29.5.861.

WALSH, G. C. Host range and reproductive traits of Diabrotica speciosa (Germar) and Diabrotica viridula (F.) 
(Coleoptera: Chrysomelidae), two species of South America pest rootworms, with notes on other species of Diabro- ticina. Environmental Entomology, Lanham, v. 32, n. 2, p. 276-285, 2003.

DOI: $10.1603 / 0046-225 X-32.2 .276$. 